\title{
NEW BOUNDS FOR THE RATIO OF POWER MEANS
}

\section{Zsolt PÁles and Paweł PasteczKa}

Abstract. We show that for real numbers $p, q$ with $q<p$, and the related power means $\mathscr{P}_{p}$, $\mathscr{P}_{q}$, the inequality

$$
\frac{\mathscr{P}_{p}(x)}{\mathscr{P}_{q}(x)} \leqslant \exp \left(\frac{p-q}{8} \cdot\left(\ln \left(\frac{\max x}{\min x}\right)\right)^{2}\right)
$$

holds for every vector $x$ of positive reals. Moreover we prove that, for all such pairs $(p, q)$, the constant $\frac{p-q}{8}$ is sharp.

Mathematics subject classification (2020): 26E60, 26D15, $26 \mathrm{D} 07$.

Keywords and phrases: Hölder means, power means, ratio bounds.

\section{REFERENCES}

[1] J. M. Borwein And P. B. Borwein, Pi and the AGM, Canadian Mathematical Society Series of Monographs and Advanced Texts, John Wiley \& Sons, Inc., New York, 1987. A study in analytic number theory and computational complexity, A Wiley-Interscience Publication.

[2] G. T. Cargo And O. Shisha, Bounds on Ratios of Means, Journal of research of the National Bureau of Standards-B, Mathematics and Mathematical Physics, 66B (4): 169-170, 1962.

[3] L. V. Kantorovich, Functional analysis and applied mathematics, Uspekhi Mat., 28 (6): 89-185, 1948. 